NASA told

to delay space mission with European scientists

A US congressional committee last week directed the National Aeronautics and Space Administration to impose a two-year delay on a joint solar research project with European scientists, the International Solar Polar Mission.

The House Appropriations Subcommittee responsible for NASA's budget said the delay was necessary because of difficulties faced in the development of the space shuttle, from which two spacecraft would be launched simultaneously to orbit the sun in opposite directions.

In addition, the subcommittee has told NASA that both the solar polar mission and the planned Project Galileo mission to Jupiter, which the agency has already suggested postponing from 1982 to 1984 , should use modified Centaur rockets for the launch from the shuttle, rather than the 'inertial upper stage' (IUS) currently under development by the US Air Force.

The instructions were contained in a letter to Dr Robert Frosch, administrator of NASA, from Appropriations Subcommittee chairman $\mathrm{Mr}$ Edward Boland. Two years ago Mr Boland tried to persuade the House of Representatives that Project Galileo should be killed entirely, and was only defeated after intensive lobbying by the space science community.

The legal status of the directive is unclear, since any change of plan would need to be endorsed by at least three other congressional committees. But with the space shuttle running into increasing delays and rising costs, space science projects have become vulnerable prey to budgetcutting politicians.

The solar-polar mission is a joint effort between NASA and the European Space Agency. The two spacecraft are currently scheduled to be launched in February 1983, and after a fly past Jupiter to enter polar orbits around the Sun in 1987.

Problems have arisen because delays in the shuttle development programme now over a year behind schedule - have contributed to difficulties in guaranteeing that the IUS could be developed sufficiently fast to provide the thrust needed to launch the two spacecraft from the shuttle by the planned date.

Similar problems have affected the Galileo project, which is also planned by NASA to use the IUS, and for which NASA has now decided that there should be separate launches for the probe and the orbiter in 1984. Previously it had been

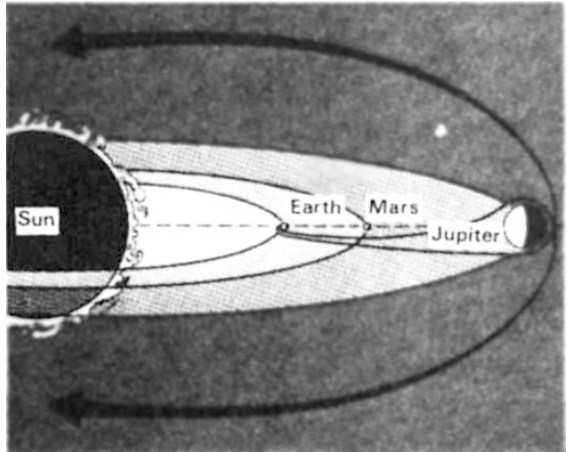

Planned trajectories of the ISPM spacecraft: a 2-year delay will add greater strain to ESA's badly stretched space science budget.

planned that both vehicles would be launched simultaneously by the IUS, but this could only have been done with a 1982 launch making use of the extra pull from the planet Mars.

Last summer NASA had rejected the Centaur as an alternative to the IUS, largely because of the extra development costs, which it calculated would have added an extra $\$ 100$ million to the cost of Galileo, whose predicted budget has already risen from $\$ 450$ million to $\$ 675$ million because of the time delay.

In his letter to $\mathrm{Mr}$ Frosch, however, $\mathrm{Mr}$ Boland says that his subcommittee will only let Galileo proceed "if NASA develops a Centaur upper stage designed to fly a combined orbiter-probe Galileo mission in 1984", and that the solar-polar mission, also using the Centaur, must be put back to 1985 .

ESA officials point out that, under their agreement with NASA, the US agency would have to bear any additional launch costs for the solar-polar mission. However they are seriously worried about the effects of a two-year delay, not only because of the extra costs of keeping scientific and technical teams together, but because it could initially mean the underutilisation of a small space science budget, as well as upsetting medium-term budget priorities.

NASA received more bad news last week, when the Office of Management and Budget rejected several proposals for new programme starts which the agency had submitted for possible inclusion in the President's budget request to Congress for the fiscal year 1981. The only new start to have received OMB's blessing is said to be the proposed launching of a gamma ray observatory. However the budget office has not supported NASA's request to start development work on a propulsion system necessary if a joint mission is to be carried out for encounters with Halley's Comet and the Comet Tempel 2 in 1985.

NASA officials are now hoping that the White House can be persauded to support some of the projects deleted by OMB. In particular discussions are taking place over joint sponsorship between the Department of Defense, the Commerce Department, and NASA about establishing a national oceanic satellite system, a successor to the ill-fated SEASAT.

\section{UN split over science policy machinery}

Member countries of the United Nations remain sharply divided over the type of internal machinery that the UN should set up to help implement decisions reached by the Conference on Science and Technology for Development (UNCSTD) held in Vienna in August.

At stake is the future of the Office of Science and Technology, currently the prime focus for science policy activities within the UN, but which many developing countries consider inappropriate, in its present form, to an expanded role.

Delegates attending the second committee of the UN General Assembly in New York last week, which is examining the conclusions of the conference, voiced unanimous approval for its decision to establish a new Intergovernmental Committee for Science and Technology for Development (IGC) open to all member states of the UN.

As in Vienna, however, opinion is divided over the nature of the secretariat which will service this committee. Many developed countries, and in particular the nine member countries of the European Economic Community, expressed their opposition to any new institutional machinery. They argue that the IGC could be adequately serviced by a strengthened department of International Economic and Social Affairs, under which OST now operates.

The Group of 77 however, which has been negotiating for the developing countries, has called for the abolition of the OST, and for its function and resources to be transferred to a new, independent secretariat, headed by an under-secretary general directly responsible to the DirectorGeneral for Development and International Economic Cooperation, $\mathrm{Mr}$ Kenneth Dadzie.

Mr Dadzie has himself offered a compromise solution which would create a new secretariat, but keep some resources within the Department of International Economic and Social Affairs. However many delegates feel that a clear division of responsibilities is necessary, and Mr Frank $\mathrm{Da}$ Costa, Secretary-General for the UNCSTD conference, has argued strongly that the Group of 77's proposal should be accepted.

After two days of open session, the second committee adjourned for informal discussions on the alternative proposals. A final decision is expected next week.

In addition to servicing the IGC, the new secretariat would be responsible both for co-ordinating science and technology activities within the UN system, and for providing support to the group of experts which the IGC will set up to study plans for a new financing system for science and technology for development. 